\title{
An oscillation theorem for a superlinear functional differential equation with general deviating arguments
}

\section{Yuichi Kitamura and Takaŝi Kusano}

An oscillation criterion is established for a class of functional differential equations including the generalized Emden-Fowler equation

$$
x^{(n)}(t)+p(t)|x(g(t))|^{\gamma} \operatorname{sgn} x(g(t))=0, \gamma>1,
$$

as a special case. The deviating arguments involved may be retarded or advanced or otherwise. The result extends and improves known fundamental oscillation criteria for superlinear differential equations with retarded arguments.

The oscillatory behaviour of functional differential equations with deviating arguments has been the object of intensive studies in the last ten years. Most of the literature, however, is concerned with equations involving retarded arguments. For typicaloscillation results regarding such equations we refer to an excellent survey article of Mitropol'ski T, Sevelo [7].

A systematic study of differential equations with general (not necessarily retarded) deviating arguments was proposed by the present authors; see, for example, [2] and [6]. As an illustration we mention the following theorem proven in [2].

THEOREM A. Consider the superlinear equation

Received 10 February 1978. 
(A)

$$
x^{(n)}(t)+p(t)|x(g(t))|^{\gamma} \operatorname{sgn} x(g(t))=0, \gamma>1,
$$

where $p, g \in C\left[R_{+}, R_{+}\right], R_{+}=[0, \infty)$, and $\lim _{t \rightarrow \infty} g(t)=\infty$. Suppose that there is a function $h \in C^{\lambda}\left[R_{+}, R_{+}\right]$such that

$$
h(t) \leq \min \{g(t), t\}, \quad h^{\prime}(t) \geq 0, \lim _{t \rightarrow \infty} h(t)=\infty,
$$

$$
\int^{\infty}[h(t)]^{n-1} p(t) d t=\infty
$$

Then, if $n$ is even, every solution $x(t)$ of (A) is oscizlatory, while, if $n$ is odd, every solution $x(t)$ is either oscillatory or such that $\left|x^{(i)}(t)\right| \downarrow 0$ as $t \uparrow \infty, i=0,1, \ldots, n-1$.

In this note we consider the differential equation

$$
x^{(n)}(t)+f\left(t, x\left(g_{1}(t)\right), \ldots, x\left(g_{m}(t)\right)\right)=0
$$

in generalization of (A) and wish to establish an oscillation criterion for (B) which generalizes earlier standard oscillation criteria for retarded differential equations $([3,4,5,8,9,10])$. Our result, when specialized to (A), turns out to be a substantial improvement of Theorem A stated above.

The conditions we assume for (B) are as follows:

(a) $g_{i} \in C\left[R_{+}, R\right], R=(-\infty, \infty)$, and $\lim _{t \rightarrow \infty} g_{i}(t)=\infty$, $i=1, \ldots, m$;

(b) $f \in C\left[R_{+} \times R^{m}, R\right], f\left(t, y_{1}, \ldots, y_{m}\right)$ is nondecreasing in each $y_{i}$, and $y_{1} f\left(t, y_{1}, \ldots, y_{m}\right)>0$ for $y_{1} y_{i}>0$, $i=1, \ldots, m$;

(c) there exist functions $p, \phi, \psi \in C\left[R_{+}, R_{+}\right]$such that $\phi(r)$ and $\psi(r)$ are nondecreasing and positive for $r>0$, $|f(t, y, \ldots, y)| \geq p(t) \phi(|y|)$ for $(t, y) \in R_{+} \times R$, and

$$
\int_{\delta}^{\infty} \frac{d r}{\phi(r) \psi(r)}<\infty \text { for any } \delta>0 \text {. }
$$


THEOREM B. Let conditions (a), (b), and (c) be satisfied. Put $g_{*}(t)=\min \left\{g_{1}(t), \ldots, g_{m}(t), t\right\}$ and suppose that

$$
\int^{\infty} \frac{\left[g_{*}(t)\right]^{n-1} p(t)}{\psi\left(\left[g_{*}(t)\right]^{n-1}\right)} d t=\infty
$$

Then, if $n$ is even, every solution $x(t)$ of (B) is oscillatory, while, if $n$ is odd, every solution $x(t)$ is either oscizlatory or such that $\left|x^{(i)}(t)\right| \downarrow 0$ as $t \uparrow \infty, i=0,1, \ldots, n-1$.

Proof. Let $x(t)$ be a non-oscillatory solution of (B) defined on $\left[T_{x}, \infty\right)$. Without loss of generality we may suppose that $x(t)>0$ on $\left[T_{x}, \infty\right)$. Choose a $t_{0} \geq T_{x}$ so large that $g_{*}(t) \geq T_{x}$ for $t \geq t_{0}$. From $(B), x^{(n)}(t)<0$ for $t \geq t_{0}$, so that by a lemma of Kiguradze [1, Lemma 2] there exists a $t_{1}>t_{0}$ and an integer $k \in\{0,1, \ldots, n-1\}$ such that $k \neq n(\bmod 2)$ and

$$
\begin{aligned}
x^{(i)}(t) & >0 \text { for } t \geq t_{1}, i=0,1, \ldots, k, \\
(-1)^{i-k_{x}(i)}(t) & >0 \text { for } t \geq t_{1}, i=k+1, \ldots, n .
\end{aligned}
$$

Let $n$ be even. Clearly $k \geq 1$ and so $x^{\prime}(t)>0$ for $t \geq t_{1}$. We claim that

$$
x^{\prime}(t) \geq \frac{\left(t-t_{1}\right)^{k-1}}{(k-1) !} \int_{t}^{\infty} \frac{(s-t)^{n-k-1}}{(n-k-1) !} f(s, \tilde{x}(\tilde{g}(s))) d s, \quad t \geq t_{1},
$$

where $\tilde{x}(\tilde{g}(s))$ stands for $\left(x\left(g_{1}(s)\right), \ldots, x\left(g_{m}(s)\right)\right)$. Observe that

$$
x^{(k)}(t)=\sum_{i=k}^{n-1} \frac{(t-T)^{i-k}}{(i-k) !} x^{(i)}(T)+(-1)^{n-k-1} \int_{T}^{t} \frac{(s-t)^{n-k-1}}{(n-k-1) !} x^{(n)}(s) d s
$$

for any $t, T \geq t_{1}$. Since (6) holds and $n-k-1$ is even, it follows from the above that

$$
x^{(k)}(t) \geq-\int_{t}^{T} \frac{(s-t)^{n-k-1}}{(n-k-1) !} x^{(n)}(s) d s
$$

for $T \geq t \geq t_{1}$, which in the limit as $T \rightarrow \infty$ gives 


$$
x^{(k)}(t) \geq \int_{t}^{\infty} \frac{(s-t)^{n-k-1}}{(n-k-1) !} f(s, \tilde{x}(\tilde{g}(s))) d s, \quad t \geq t_{1} .
$$

This coincides with ( 7 ) if $k=1$. Suppose $k \geq 2$. Then we have

$$
x^{\prime}(t) \geq \frac{\left(t-t_{1}\right)^{k-1}}{(k-1) !} x^{(k)}(t), \quad t \geq t_{1} .
$$

This follows from the equation

$$
x^{\prime}(t)=\sum_{i=1}^{k-1} \frac{\left(t-t_{1}\right)^{i-1}}{(i-1) !} x^{(i)}\left(t_{1}\right)+\int_{t_{1}}^{t} \frac{(t-s)^{k-2}}{(k-2) !} x^{(k)}(s) d s
$$

with the aid of (5) and the decreasing nature of $x^{(k)}(t)$. Combining (8) with (9) yields (7) as claimed.

We now take a $t_{2}>t_{1}$ so that $g_{*}(t) \geq t_{1}$ for $t \geq t_{2}$. Since $x^{(n)}(t)<0$ for $t \geq t_{0}$, there is a constant $a \geq 1$ such that $x(t) \leq a t^{n-1}$ for $t \geq t_{1}$, and hence if $s \geq t_{2}$, then

$$
x(t) / a \leq\left[g_{*}(s)\right]^{n-1} \text { for } t_{1} \leq t \leq g_{*}(s) \text {. }
$$

We divide both sides of (7) by $\phi(x(t) / a) \psi(x(t) / a)$ and integrate it over $\left[t_{1}, t_{3}\right], t_{3}>t_{2}$, obtaining

$$
\begin{aligned}
& \int_{t_{1}}^{t_{3}} \frac{x^{\prime}(t)}{\phi(x(t) / a) \psi(x(t) / a)} d t \\
& \quad \geq \int_{t_{1}}^{t_{3}} \frac{\left(t-t_{1}\right)^{k-1}}{(k-1) ! \phi(x(t) / a) \psi(x(t) / a)} \int_{t}^{t_{3}} \frac{(s-t)^{n-k-1}}{(n-k-1) !} f(s, \tilde{x}(\tilde{g}(s))) d s d t \\
& \quad=\int_{t_{1}}^{t_{3}} \int_{t_{1}}^{s} \frac{(s-t)^{n-k-1}\left(t-t_{1}\right)^{k-1}}{(n-k-1) !(k-1) !} \frac{f(s, \tilde{x}(\tilde{g}(s)))}{\phi(x(t) / a) \psi(x(t) / a)} d t d s \\
& \geq \int_{t_{2}}^{t_{3}} \int_{t_{1}}^{g_{*}(s)} \frac{\left(g_{*}(s)-t^{n}\right)^{n-k-1}\left(t-t_{1}\right)^{k-1}}{(n-k-1) !(k-1) !} \frac{f(s, \tilde{x}(\tilde{g}(s))]}{\phi(x(t) / a) \psi(x(t) / a)} d t d s .
\end{aligned}
$$

Noting that $x(t)$ is increasing and using (b), (c), and (10), we see that 
if $t_{2} \leq s \leq t_{3}$, then

$$
\begin{aligned}
\frac{f(s, \tilde{x}(\tilde{g}(s))]}{\phi(x(t) / a) \psi(x(t) / a)} & \geq \frac{\phi\left(x\left(g_{*}(s)\right)\right)}{\phi(x(t))} \frac{p(s)}{\psi(x(t) / a)} \\
& \geq \frac{p(s)}{\psi\left(\left[g_{*}(s)\right]^{n-1}\right)} \text { for } t_{1} \leq t \leq g_{*}(s) .
\end{aligned}
$$

From the above observations it follows that

$$
\int_{t_{2}}^{t_{3}} \frac{\left[g_{*}(s)-t_{1}\right]^{n-1} p(s)}{\psi\left(\left[g_{*}(s)\right]^{n-1}\right)} d s \leq a(n-1) ! \int_{x\left(t_{1}\right) / a}^{x\left(t_{3}\right) / a} \frac{d r}{\phi(r) \psi(r)} .
$$

In view of (3), letting $t_{3} \rightarrow \infty$ in (II), we conclude that

$$
\int_{t_{2}}^{\infty} \frac{\left[g_{*}(s)-t_{1}\right]^{n-1} p(s)}{\psi\left(\left[g_{*}(s)\right]^{n-1}\right)} d s<\infty
$$

which contradicts (4). Thus, if $n$ is even, then all solutions of (B) oscillate.

Let $n$ be odd. If the integer $k$ in (5) and (6) is positive, then the same argument as above leads to a contradiction. Therefore, $k$ must be zero and we have

$$
x(t)+c \geq 0,\left|x^{(i)}(t)\right|+0 \text { as } t \uparrow \infty, i=1, \ldots, n-1 .
$$

Suppose $c>0$. Then from $(B)$ we get

$$
x^{(n)}(t)+\phi(c) p(t) \leq 0 \text { for } t \geq t_{2} \text {. }
$$

An integration of (12) multiplied by $\left(t-t_{2}\right)^{n-1} /(n-1) !$ yields

$$
\phi(c) \int_{t_{2}}^{t} \frac{\left(s-t_{2}\right)^{n-1}}{(n-1) !} p(s) d s+\sum_{i=0}^{n-1} \frac{\left(t-t_{2}\right)^{i}}{i !}(-1)^{i} x^{(i)}(t)-x\left(t_{2}\right) \leq 0
$$

for $t \geq t_{2}$, from which, taking (6) into account, we obtain

$$
\int_{t_{2}}^{\infty}\left(s-t_{2}\right)^{n-1} p(s) d s<\infty
$$


But this clearly contradicts (4), and so $c$ must be zero. Thus the proof is complete.

Applying Theorem B to the particular case where

$$
f\left(t, y_{1}, \ldots, y_{m}\right)=p(t) \prod_{i=1}^{m}\left|y_{i}\right|^{Y_{i}} \operatorname{sgn} y_{1},
$$

we have the following

COROLLARY C. Consider the differential equation

$$
x^{(n)}(t)+p(t) \prod_{i=1}^{m}\left|x\left(g_{i}(t)\right)\right|^{\gamma_{i}} \operatorname{sgn} x\left(g_{1}(t)\right)=0 \text {, }
$$

where $\gamma_{i}, i=1, \ldots, m$, are nonnegative constants. If $\gamma_{1}+\ldots+\gamma_{m}>1$ and

$$
\int^{\infty}\left[g_{*}(t)\right]^{n-1} p(t) d t=\infty
$$

then, for $n$ even, every solution $x(t)$ of $(c)$ is oscillatory, and, for $n$ odd, every solution $x(t)$ is either oscizlatory or such that $\left|x^{(i)}(t)\right|+0$ as $t \uparrow \infty, i=0,1, \ldots, n-1$.

We give an example which shows that Corollary $C$ actually improves Theorem A.

EXAMPLE. Consider the equation

$$
x^{\prime \prime}(t)+t^{-7 / 4}[x(g(t))]^{3}=0, g(t)=t+\left(t-t^{\frac{3}{2}}\right) \sin t .
$$

Since $g_{*}(t)=t$ for $2 k \pi \leq t \leq(2 k+1) \pi, k=1,2, \ldots$, we have

$$
\begin{aligned}
\int_{2 \pi}^{\infty} t^{-7 / 4} g_{*}(t) d t & \geq \sum_{k=1}^{\infty} \int_{2 k \pi}^{(2 k+1) \pi} t^{-7 / 4} \cdot t d t \\
& \geq \pi \sum_{k=1}^{\infty}[(2 k+1) \pi]^{-3 / 4}=\infty .
\end{aligned}
$$

Hence, by Corollary C, all solutions of (13) are oscillatory.

On the other hand, Theorem A cannot be applied to (13), for there does not exist a function $h(t)$ which satisfies both (1) and (2). In fact, if $h(t)$ is any function satisfying $(1)$, then 


$$
\begin{aligned}
& h(t) \leq h((2 k+(3 / 2)) \pi) \leq g((2 k+(3 / 2)) \pi)=[(2 k+(3 / 2)) \pi]^{1 / 2} \\
& \text { for }(2 k-(1 / 2)) \pi \leq t \leq(2 k+(3 / 2)) \pi, k=1,2, \ldots \text {, so that we find } \\
& \int_{3 \pi / 2}^{\infty} t^{-7 / 4} h(t) d t=\sum_{k=1}^{\infty} \int_{(2 k-1 / 2) \pi}^{(2 k+3 / 2) \pi} t^{-7 / 4} h(t) d t \\
& \leq 2 \pi \sum_{k=1}^{\infty}[(2 k-(1 / 2)) \pi]^{-7 / 4}[(2 k+(3 / 2)) \pi]^{1 / 2}<\infty .
\end{aligned}
$$

\section{References}

[1] Н.Т. Нигурадзе [1.Т. Kiguradze], "О нолеблемостн решений уравнения $\frac{d^{m} u}{d t^{m}}+a(t)|u|^{n}$ sign $u=0 "$ [On the oscillation of solutions of the equation $\left.\frac{d^{m} u}{d t^{m}}+a(t)|u|^{n} \operatorname{sign} u=0\right]$, Mat. Sb. (N.S.) 65 (107) (1964), 172-187.

[2] Yuichi kitamura, "On nonoscillatory solutions of functional differential equations with a general deviating argument", Hiroshima Math. J. 8 (1978), 49-62.

[3] TakaŜi Kusano and Hiroshi Onose, "Oscillation of solutions of nonlinear differential delay equations of arbitrary order", Hiroshima Math. J. 2 (1972), 1-13.

[4] Takaŝi Kusano and Hiroshi Onose, "Oscillation theorems for delay equations of arbitrary order", Hiroshima Math. J. 2 (1972), $263-270$.

[5] T. Kusano and $H$. Onose, "Oscillations of functional differential equations with retarded argument", J. Differential Equations 15 (1974), 269-277.

[6] Takaŝi Kusano and Hiroshi Onose, "Nonlinear oscillation of second order functional differential equations with advanced argument", J. Math. Soc. Japan 29 (1977), 541-559. 
[7] Н.А. Мнтропольсний, В.Н. Шевело [Ju.A. Mitropol'skiT, V.N. Sevelo], "О развнтин теории осцилляции решений дифференциальных уравнений с запаздыванинм аргументом" [On the development of the theory of oscillation of solutions of differential equations with retarded argument], Ukrain. Mat. Z. 29 (1977), 313-323.

[8] B.H. Шевело, Н.B. Варех [V.N. Sevelo, N.V. Vareh], "О нолеблемостн решеннй линейных днфференцнальных уравнений высшнх поряднов с запаздывающим аргументом" [On the oscillation of solutions of higher order linear differential equations with retarded argument], Ukrain. Mat. ̌̌. 24 (1972), 513-520.

[9] B.H. Шевело, Н.В. Варех [V.N. Ševelo, N.V. Vareh], "О неноторых свойствах решений дифференцнальных уравненнй с эапаздыванием" [On some properties of solutions of differential equations with delay], Ukrain. Mat. 2. 24 (1972), 807-813.

[10] V.G. Sficas and V.A. Staikos, "Oscillations of retarded differential equations", Proc. Combridge Phizos. Soc. 75 (1974), 95-101.

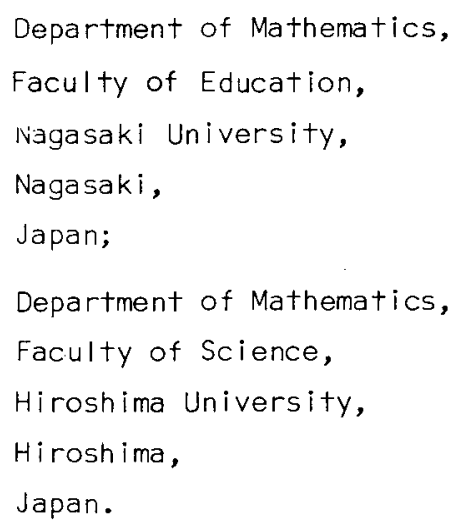

